\title{
The effect of processing parameters on particle size in ammonia-induced precipitation of zirconyl chloride under industrially relevant conditions.
}

\author{
G. A. Carter, ${ }^{a+b}$ R. D. Hart, ${ }^{b}$ M . R. Rowles, ${ }^{c}$ C. E. Buckley ${ }^{b}$ and M. I. Ogden ${ }^{*}$ \\ ${ }^{a}$ Nanochemistry Research Institute, Curtin University of Technology, PO Box U1987, Perth, Western \\ Australia, 6845, Australia \\ ${ }^{b}$ Centre for Materials Research, Curtin University of Technology, PO Box U1987, Perth, Western \\ Australia, 6845, Australia \\ ${ }^{c}$ Commonwealth Scientific Industrial Research Organisation (CSIRO) Minerals Clayton South, \\ Victoria Australia
}

\begin{abstract}
The effect of $\mathrm{pH}$ of precipitation, starting solution concentration, and agitation levels on the particle size of hydrous zirconia precipitates have been investigated. It was found that all three variables affect the particle size of the hydrous zirconia. The smallest particle size is produced by a $0.81 \mathrm{M}$ starting solution, precipitated at $\mathrm{pH} 12$ with a high agitation level. The $\mathrm{pH}$ of precipitation was also found to have a significant impact on the type of hydrous zirconia produced. TGA/DTA, micro combustion and TEM / EDS were used to investigate the difference in the powders produced at $\mathrm{pH} 3$ and 12. This work suggests that powders produced at $\mathrm{pH} 3$ will have a structure similar to $\mathrm{Zr}[\mathrm{OH}]_{4}$ whilst those at $\mathrm{pH} 12$ are more likely $\mathrm{ZrO}[\mathrm{OH}]_{2}$. XRD and micro-combustion suggest that the powders produced at $\mathrm{pH} 3$ retained ammonium chloride whilst those produced at $\mathrm{pH} 12$ did not. The filtration rates for the $\mathrm{pH} 3$ product were significantly faster than that of the powders made at $\mathrm{pH} 12$ which is significant in the industrial production of these materials.
\end{abstract}

Keywords: zirconia; precipitation; particle size; zirconyl chloride.

Corresponding Author current affiliation Nanochemistry Research Institute, Curtin University of Technology, PO Box U1987, Perth, Western Australia, 6845, Australia Tel:- +61 89266 2483, Fax:- +61 892664699 Email:

m.ogden@exchange.curtin.edu.au 


\section{Introduction}

Recent studies of hydrous zirconia for the eventual preparation of yttria stabilised zirconia have investigated the formation of hard agglomerates produced during aqueous precipitation of hydrous zirconia precursor from zirconyl chloride solutions [1]The formation of these hard agglomerates is industrially relevant as they are a significant impediment to the use of these materials in the large scale production of ceramic powders for purposes such as solid oxide fuel cells [2, 3]. While not the primary focus of the reported studies, literature suggests both zirconium species and precipitate particle size can be affected by the $\mathrm{pH}$ of precipitation, concentration and agitation rate $[4,5]$. These properties are crucial in the industrial processing of these powders as they impact on parameters such as filtration rates and rheology. These effects eventually result in processing and performance issues in the ceramics produced [1].

Larsen and Gammill [6] conducted electrometric titration studies on zirconium and hafnium using zirconyl and hafnyl chlorides as the base solutions. They produced tables and curves showing precipitation occurs for zirconium at $\mathrm{pH}$ of approximately 2 and coagulation occurred $\mathrm{pH} \sim 6$. The hafnium curve shows little difference in the precipitation points or coagulation points from the zirconyl solution.

Later extensive work by Clearfield [4] suggested the precipitation process was a hydrolytic polymerisation, and that the precipitation occurred at a low $\mathrm{pH}$ and was completed before the end point of neutralisation is reached. Clearfield explains that this is due to the retention of anions by the precipitate and that the amount of anion retention is dependent on $\mathrm{pH}$, decreasing as the $\mathrm{pH}$ of precipitation increases. It was suggested that this behaviour indicates that the precipitates should be viewed as basic salts of variable composition [4]. Larsen and Gammill [6] also postulated the formation of basic salts by zirconium compounds and used this to explain differences found between the precipitation of hafnium and zirconium with respect to chloride ion content. The range of $\mathrm{pH}$ values for the precipitation points for differing concentrations of chloride ions was 1.88 to 2.29 [6]. These values agree with the results of Kovalenko and Bagdasaov [7] who conducted dissolution studies on what they call solid $\mathrm{Zr}(\mathrm{OH})_{4}$ where they found that dissolution in nitric acid occurs at a $\mathrm{pH}$ of 1.9 and increases up to a pH of 1.8. They suggest that the precipitation must occur at these $\mathrm{pH}$ values as well. The solubility product was also calculated using a stoichiometric formula of $\operatorname{Zr}(\mathrm{OH})_{4}$ although it is made clear in the paper that this formula is an assumption. Huang et al [8] $\underline{\text { investigated the differences between zirconium hydroxide }\left(\mathrm{Zr}(\mathrm{OH})_{4}\right.} \underline{\mathrm{nH}_{2}} \underline{\underline{\mathrm{O}}) \text { and hydrous }}$ $\underline{\text { zirconia }\left(\mathrm{ZrO}_{2}\right.} \cdot \underline{\mathrm{nH}_{2}} \underline{\underline{O}) \text { but did not investigate the previously suggested structure } \mathrm{ZrO}(\mathrm{OH})_{2}} \underline{[9}$, 10] [11][12] [13]. 
The nature of zirconium hydroxide species precipitated under acidic conditions have also been investigated using thermal and x-ray techniques $[14,15]$. The suggested structure, which differs from the previous literature, is $\mathrm{Zr}_{4} \mathrm{O}_{3}(\mathrm{OH})_{10} \cdot 6 \mathrm{H}_{2} \mathrm{O}$. The authors compare this structure with $\alpha-\mathrm{Zr}_{4}(\mathrm{OH})_{16}, \beta-\mathrm{Zr}_{4} \mathrm{O}_{2}(\mathrm{OH})_{12}$ and $\gamma-\mathrm{Zr}_{4} \mathrm{O}(\mathrm{OH})_{8}$ with the major difference being the coordinated water ([14] and references therein). The suggested structure for hydroxides produced at $\mathrm{pH} 4$ and 3 are the same although no data are shown for the $\mathrm{pH} 3$ sample [14].

Clearfield [16] reviews a number of the papers discussed in [14] and points out that the majority of these authors have neglected the work he completed [4] in their assessments of the polymerisation process that zirconium undergoes. He reiterates that the differences seen in the polymorphs of zirconia after calcination can be related to the speed at which the zirconia is produced, with a slower process leading to a more ordered structure that thus forms the tetragonal polymorph and a faster reaction leading to monoclinic. Whilst not directly linked to the wet chemistry, the polymorphs produced have been reported to be associated with crystallite size, with a transition from tetragonal to monoclinic occurring when crystallites grow above $30 \mathrm{~nm}$ [17].

Roosen and Hauser discuss some ways in which agglomeration of precipitates can be influenced, listing nucleation rate and nucleation growth as being important to the strength of the agglomerates formed within the precipitation process [18]. In this case the term agglomerates is used to describe; "a limited arrangement of primary particles, which forms a network of interconnective pores”. The primary particles are held together by adhesion forces which are fully discussed in [19]. The strength of such agglomerates can also be influenced by important precipitation parameters such as temperature, $\mathrm{pH}$, concentration and type of reagents and solvents, sequence of mixing, reaction rate, method of mixing as well as the aging of the precipitates [18] [20].

The authors have reported previously the effects of acidity on the formation of zirconium species and the effect of concentration and counter cations on the particle size of the precipitates [1]. The current work examines in more detail the effects of $\mathrm{pH}$, concentration and agitation upon the zirconium species, precipitate particle size, and various processing parameters, thus concentrating on the variables that are simplest to control from a continuous precipitation plant operational perspective. 


\section{Experimental}

Detailed sample preparation method for all solutions are available in the literature [1] [21]. Briefly, solutions were made from zirconyl chloride crystals (supplied by Doral Specialty Chemicals Western Australia) dissolved in milli-q water. Two concentrations, 0.81 and 1.62 $\mathrm{M}$, of zirconyl chloride were used. The zirconyl chloride used had been tested for trace elements by ICP-OES and returned less than detectable results [1]. The sample solutions were aged for 10 days at ambient temperature prior to use, all samples were used within 24 hours of the 10 day aging period.

The agitation rate was measured by determining the Reynolds number which was calculated using the standard formula for impellers [22]

$$
R_{N}=\frac{\rho N D^{2}}{\mu}
$$

where

$$
\begin{aligned}
& \rho=\text { density } \\
& \mu=\text { viscosity } \\
& \mathrm{N}=\text { Rotational speed } \\
& \mathrm{D}=\text { Impeller diameter }
\end{aligned}
$$

The target Reynolds number was 10000, being above the turbulent transition zone, for what is defined below as high agitation and a Reynolds number of 5000 for the low agitation [22].

The precipitation method and particle sizing by Dynamic Light Scattering (DLS) are also detailed in [1]. In summary the zirconyl chloride solution and aqueous ammonia were injected into an agitated vessel in the same plane as the impeller rotation. The solution overflowed into a bath of ethanol, which quenches particle growth. The system was started using milli-q water run into equilibrium using four residence times at which point the bath of ethanol was changed. As discussed previously the ethanol is used as a steric hindrent to quench further particle growth [1].

The precipitate was isolated using a Whatmans $541125 \mathrm{~mm}$ diameter filter paper in Büchner funnel and vacuum flask. 304.8 Torr of vacuum was supplied by a Dynavac ODI diaphragm 
vacuum pump. To determine filtration rates $250 \mathrm{~mL}$ of suspension was poured into the Büchner funnel and the filtration rate timed. Timing was started when vacuum was applied and was stopped once the fluid was not visible within the cake.

The effect that filtering may have on the particle size distribution was investigated. Samples from the filter cakes of the $0.81 \mathrm{M}$ zirconyl chloride precipitated at both $\mathrm{pH} 3$ and 12 were taken. The cake was re-suspended by adding 5 grams of filter cake to $100 \mathrm{ml}$ of ethanol and agitated using a sonic bath for 3 minutes. The suspension was then tested using DLS.

Diffraction data were obtained using an in-situ powder XRD system. Samples were placed on a platinum sample well measuring $20.0 \times 7.0$ x $0.4 \mathrm{~mm}$. Each sample was hand ground in a mortar and pestle with ethanol and was applied directly onto the Pt sample well as a thick slurry. The X-ray data were obtained using an X-ray diffractometer incorporating an Inel CPS-120 curved, position-sensitive detector. The angular range of the detector is 120 deg $2 \theta$, facilitating rapid, simultaneous data accumulation. Data were collected in the reflection mode using $\mathrm{Cu} \mathrm{K} \alpha$ radiation operated at $35 \mathrm{kV}$ and $30 \mathrm{~mA}$. Datasets of $60 \mathrm{~s}$ in duration were collected. The XRD patterns were interpreted with the aid of Jade 6.0.3 analytical software (MDI 2003).

DTA/TGA was conducted using a TA Instruments 2969 SDT V3.0F on filter cake that had been dried in a drying oven for 48 hours at $55^{\circ} \mathrm{C}$.

Raman spectroscopy was similarly undertaken on filter cake that had been dried for 48 hours at $55^{\circ} \mathrm{C}$.

Micro-combustion analysis was conducted by Dr Thomas Rodemann of the Vibrational Spectroscopy and Elemental Analysis Central Science Laboratory, University of Tasmania.

Optical microscopy was conducted using a Nikon SMZ 800 microscope with a SPOT insight Colour Model 3.2.0 digital camera with external light. Calibration of sizing was achieved using a Graticules LTD 200x0.01 = 2mm graticule.

TEM imaging was carried out on well dispersed samples of precipitates on carbon film. Washed and dried precipitate from $0.81 \mathrm{M}$ solutions at high agitation for both 3 and $12 \mathrm{pH}$ along with calcined $\mathrm{ZrO}_{2}$, were investigated using a JEOL 2011 transmission electron microscope operated at $200 \mathrm{kV}$. Energy dispersive spectra for well separated single crystals 
were collected at 500-1500 counts per second for 100 live seconds. Elemental compositions of these crystals using calculated $\mathrm{k}$ factors were determined using the thin film method [23, 24].

\section{Results}

Table 1 shows the variation of particle size for three variables, $\mathrm{pH}$ ( 3 or 12 ), zirconyl chloride concentration $(0.81$ or $1.62 \mathrm{M})$ and agitation (high or low). All three variables were shown to significantly effect the particles size. Increased $\mathrm{pH}$ produced smaller particles, increased agitation produced smaller particles and increasing zirconyl chloride concentrations produced larger particles. The largest variation was due to changes of $\mathrm{pH}$. The particle size of the precipitates of zirconium hydroxide produced at $\mathrm{pH} 12$ are one or two orders of magnitude smaller than those produced at $\mathrm{pH} 3$; e.g. using high agitation of $0.81 \mathrm{M}$ solutions, at $\mathrm{pH} 12$ particles were $49 \mathrm{~nm}$ compared to $1130 \mathrm{~nm}$ at pH 3 (Table 1).

Precipitates produced at $\mathrm{pH} 12$ showed greater variability of particle sizes , e.g. for the 1.62 $\mathrm{M}$ solution the difference between the low and high Reynolds number agitation is approximately 10 times (73 vs 743nm). In contrast for the $\mathrm{pH} 3$ sample, the change with agitation for the 0.81 solution is only 1.5 times (1130 vs $1820 \mathrm{~nm}$ ). This could indicate that the particles produced at a higher $\mathrm{pH}$ are more prone to mechanical degradation. To test if mechanical degradation was causing the particle size differences the filter cake was redispersed in ethanol using a sonic bath. DLS was used to investigate the PSD of the resuspended materials (Figure 1). The results indicated the $\mathrm{pH} 12$ sample was effected less by the filtration and re-suspension than the sample produced at $\mathrm{pH} \mathrm{3}$, although both had a bimodal distribution. The resuspended $\mathrm{pH} 12$ sample had the majority of the particles distributed in the region of the initial precipitate, although the distribution displayed is broader. This suggests that mechanical degradation is not the major mechanism that produces the smaller particle size for the $\mathrm{pH} 12$ precipitates. We believe the higher availability of base allows a faster rate of precipitation which in turn leads to the production of smaller particles. 
Table 1 Particle size and filtration rates for varying $\mathrm{pH}$, concentrations of zirconyl chloride and agitations.

\begin{tabular}{|c|c|c|c|c|}
\hline $\mathrm{pH}$ & $\begin{array}{c}\text { Concentration of } \\
\text { starting } \\
\text { solutions }\end{array}$ & Agitation level & PSD (nm) & $\begin{array}{c}\text { Filtration rate } \\
\text { minutes }\end{array}$ \\
\hline 3 & 0.81 & Low & 1820 & 6.8 \\
\hline 3 & 0.81 & High & 1130 & 7 \\
\hline 3 & 1.62 & Low & 3390 & 4.3 \\
\hline 3 & 1.62 & High & 2160 & 5.9 \\
\hline 12 & 0.81 & Low & 309 & $>20$ \\
\hline 12 & 0.81 & High & 49 & $>60$ \\
\hline 12 & 1.62 & Low & 743 & $>15$ \\
\hline 12 & 1.62 & high & 73 & $>60$ \\
\hline
\end{tabular}

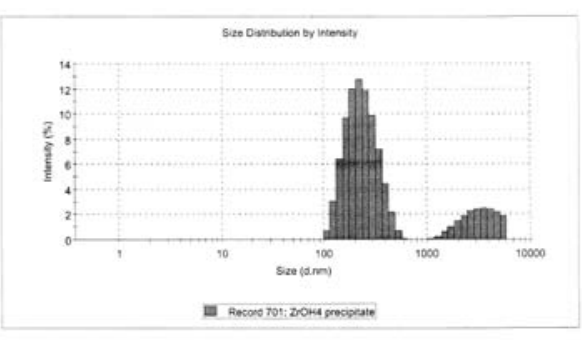

(a)

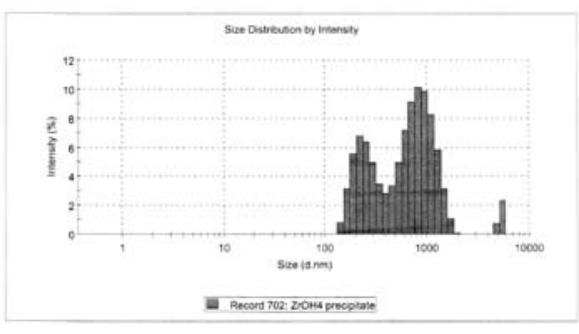

(b)

Figure 1 Histogram from DLS (intensity vs. Size) of re-suspended filter cake,(a) precipitated at $\mathrm{pH}$ 12. (b) precipitated at $\mathrm{pH} 3$.

Increased agitation generally results in smaller particles, and the results described here are consistent with that expectation. The filtration rates showed a strong dependence on particle size, as expected. Precipitates produced at $\mathrm{pH} 12$ would be unusable industrially as the time taken to filter was excessive.

Figure 2 shows optical micrographs of the dried filter cakes obtained from $0.81 \mathrm{M}$ high agitation solutions at $\mathrm{pH} 3$ and 12. Solutions precipitated at $\mathrm{pH} 12$ produced fine well divided powders whilst those produced at $\mathrm{pH} 3$ contained large aggregated particles that were difficult to break apart using a mortar and pestle. 


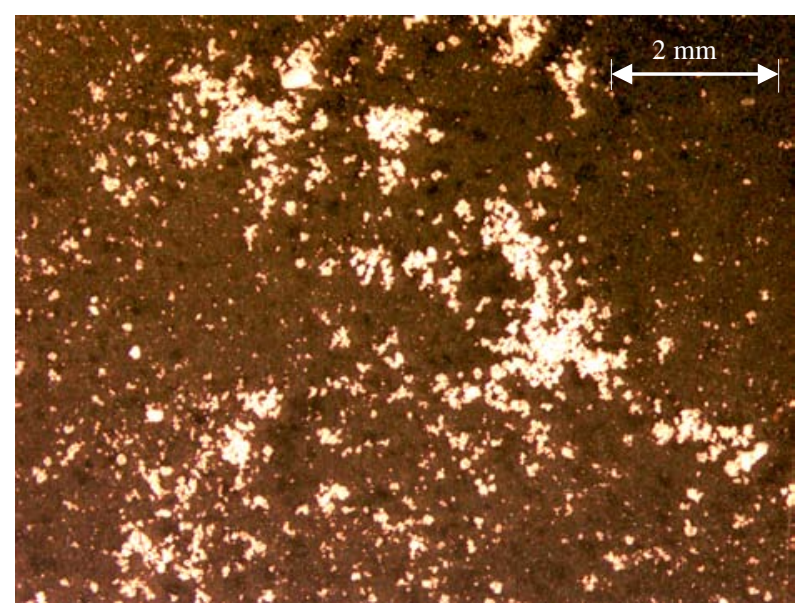

(a)

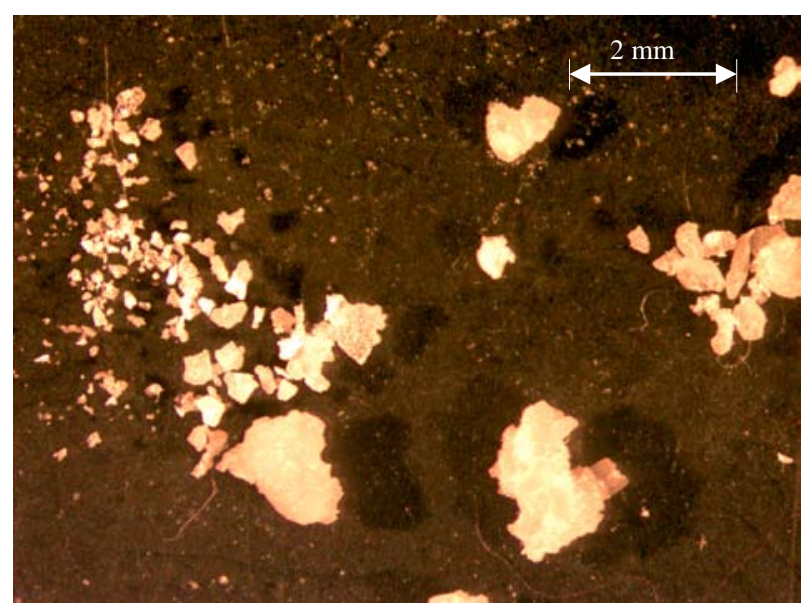

(b)

Figure 2 Optical micrograph of $0.81 \mathrm{M}$ dried precipitates (a) precipitated at $\mathrm{pH}$ 12. (b) precipitated at $\mathrm{pH} 3$.

The large differences demonstrated suggested the possibility of different zirconia phases being responsible for the varying products. The four high agitation dried precipitates were examined using powder X-Ray Diffraction (XRD) returning a mostly amorphous XRD

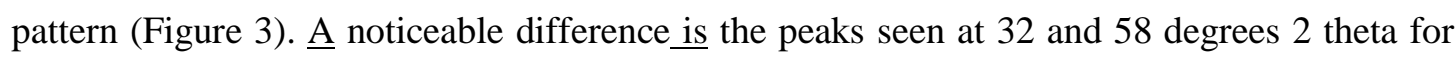
both of the $\mathrm{pH} 3$ samples which are absent in the $\mathrm{pH} 12$ samples. This is due to residual salammoniac $\left(\mathrm{NH}_{4} \mathrm{Cl}\right.$ PDF\# 07-007) The peaks observed at 39, 46, 67, 81, $86{ }^{\circ} 2 \theta$ are due to the platinum from the sample holder used (PDF\# 04-0802).

The presence of ammonium chloride in the samples produced at $\mathrm{pH} 3$, whilst making sense chemically, was counter intuitive in light of the ease with which the filtering and subsequent washing of the filter cake was achieved.

To further investigate the products Raman spectroscopy was carried out (Figure 4) but the patterns returned did not show any changes between either of the starting solution concentrations or the pH's of precipitation. Raman spectroscopy of hydrous-zirconia which was produced by refluxing aqueous zirconyl chloride solutions of differing concentrations has been reported [25]. The data presented show a dependence on solution concentration to the amount of crystallinity determined. The higher concentrations used showed a decreasing tendency to match the spectra given for monoclinic zirconia and thus it was concluded that the material is hydrous zirconia. Huang et al [8] discuss at length the differences between hydrous zirconia and zirconium hydroxide and use TGA and XRD to show the differences between the two species. 


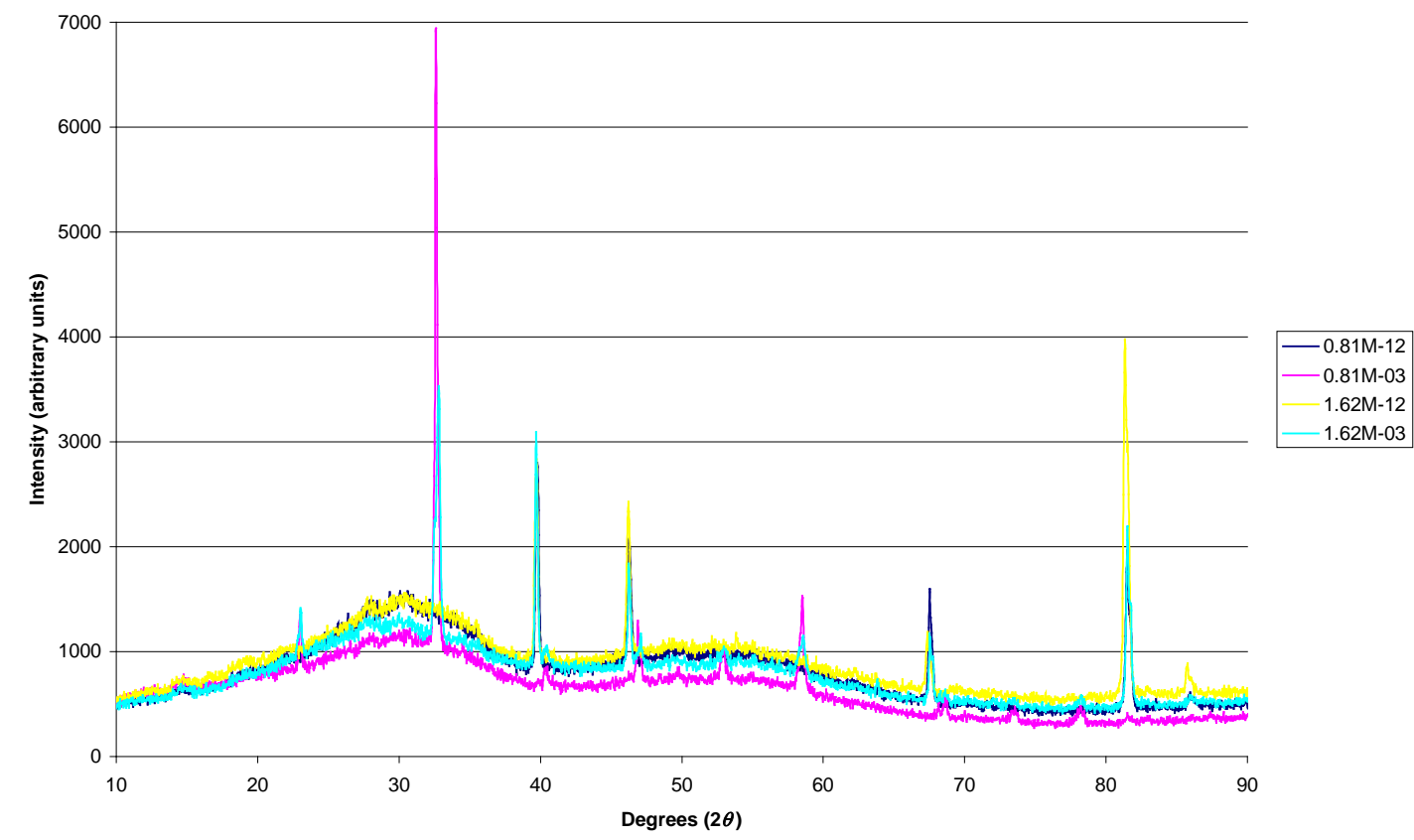

Figure $3 \mathrm{XRD}$ trace of $0.81 \mathrm{M}, 1.62 \mathrm{M}, \mathrm{pH} 3$ and 12 precipitated, dried powder showing an amorphous hump (Cu K radiation operated at $35 \mathrm{kV}$ and $30 \mathrm{~mA}$ )

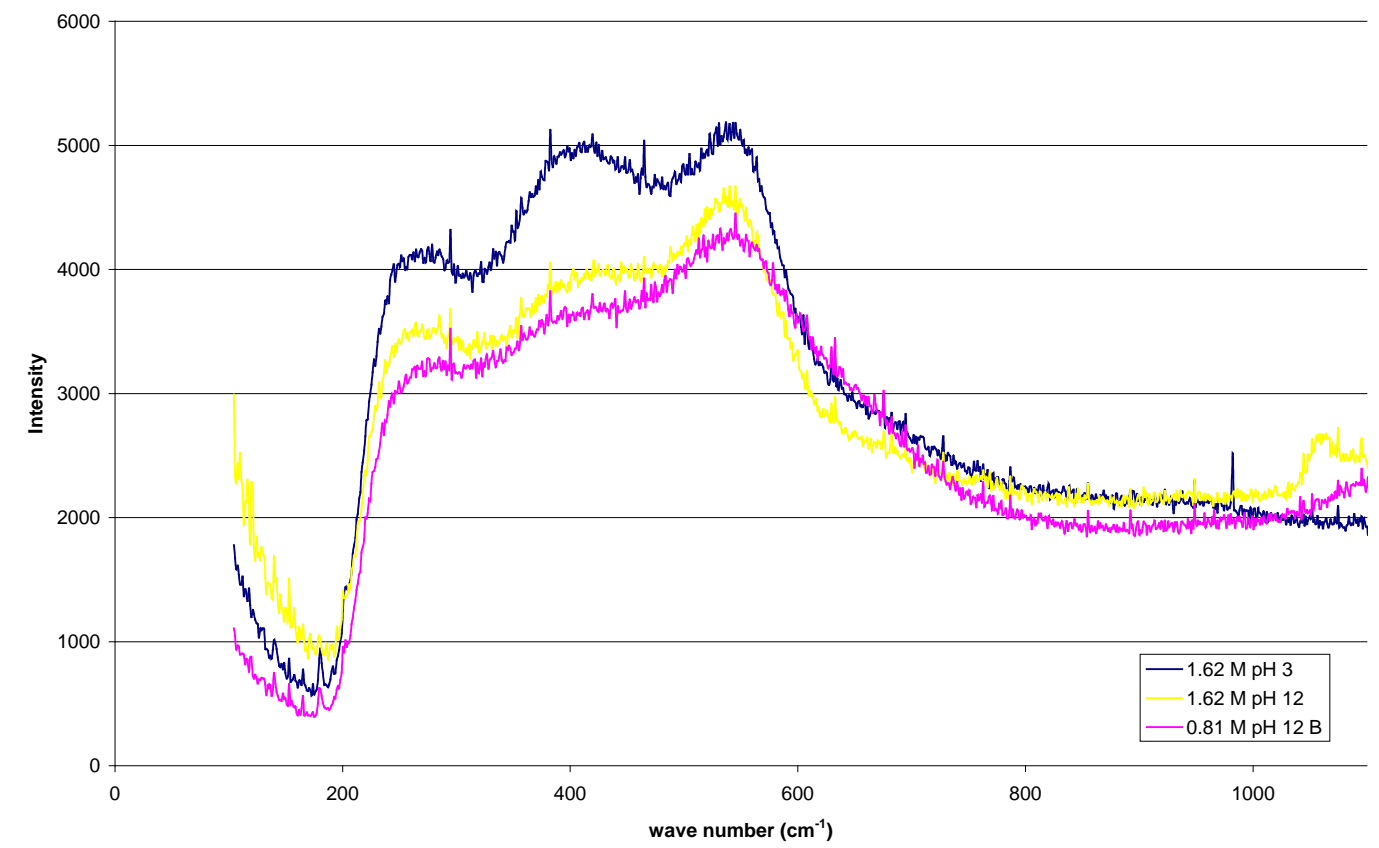

Figure 4 Raman spectra 0.81M, 1.62M, pH12 and a $1.62 \mathrm{M}$, pH 3 precipitated, dried powder. (Developed using a Dilor Labtram 1B with excitation HeNe - $632.82 \mathrm{~nm}$ and a 600 lines/mm diffraction grating) 
To investigate the differences in the powder produced by the two different $\mathrm{pH}$ values TGA/DTA was conducted (see Figure 5 and Figure 6). The mass lost for the $\mathrm{pH} 12$ product was $21 \%$, this is in close agreement to the theoretical value of $22.6 \%$ for transformation from $\mathrm{Zr}[\mathrm{OH}]_{4}$ to $\mathrm{ZrO}_{2}$ suggesting that the structure present at a $\mathrm{pH} 12$ may be $\mathrm{Zr}[\mathrm{OH}]_{4}$ (see Figure 6). Rajendran [2] shows three DTA curves where two have smooth single endothermic events the same as seen in Figure 6 whilst the third curve had two separate events similar to that found in Figure 5. The literature explanation was that the two with the smooth endotherms were produced using ethanol and that the ethanol induces the removal of the physisorbed and chemically bound water. The two powders produced using ethanol also had two exotherms reminiscent of the ones seen in Figure 6 with the first occurring around $304{ }^{\circ} \mathrm{C}$ being a broad hump with the second being a sharp exotherm. It was suggested that the first broad hump is in all likelihood related to the decomposition of zirconium ethoxide, whilst the second is due to crystallisation [2]. Similar cases can be made in the case of this work however the mass loss from the transformation to $\mathrm{ZrO}_{2}$ closely matched the expected value of $22.6 \%$ which allows the presence of little else but $\mathrm{Zr}[\mathrm{OH}]_{4}$. The $\mathrm{pH} 3$ precipitated samples that were washed in the same manner as the $\mathrm{pH} 12$ samples had ammonium chloride present as demonstrated by the $\mathrm{XRD}$, as well as water incorporated within the structure along with ethanol if reasoning such as that reported previously was to be used [2].

The presence of these additional components was tested by TGA/DTA with a mass spectrometer attached. Whilst not allowing quantitative analysis, it was expected that distinct points of evolution of water, ethanol and $\mathrm{CO}_{2}$ would be found. It was found that ethanol was evolved by both the $\mathrm{pH} 12$ and $\mathrm{pH} 3$ samples as was water and $\mathrm{CO}_{2}$. The points of evolution vary greatly between the $\mathrm{pH} 12$ and $\mathrm{pH} 3$ samples. This then does not allow for the assumption of the structure for the $\mathrm{pH} 12$ to be $\mathrm{Zr}[\mathrm{OH}]_{4}$ as no provision is made for the ethanol. However if the alternative $\left(\mathrm{ZrO}[\mathrm{OH}]_{2}\right)$ structures is assumed the theoretical change in mass from this to $\mathrm{ZrO}_{2}$ is $12.8 \%$ and this would thus allow for $8.2 \%$ of ethanol. The $\mathrm{pH} 3$ sample had a $32.5 \%$ mass loss which allows the starting structure of $\operatorname{Zr}[\mathrm{OH}]_{4}$ then as a transformation to $\mathrm{ZrO}_{2}$ would leave $9.9 \%$ of mass loss unaccounted for which is in reasonable agreement with the difference displayed by the $\mathrm{pH} 12$ sample. 


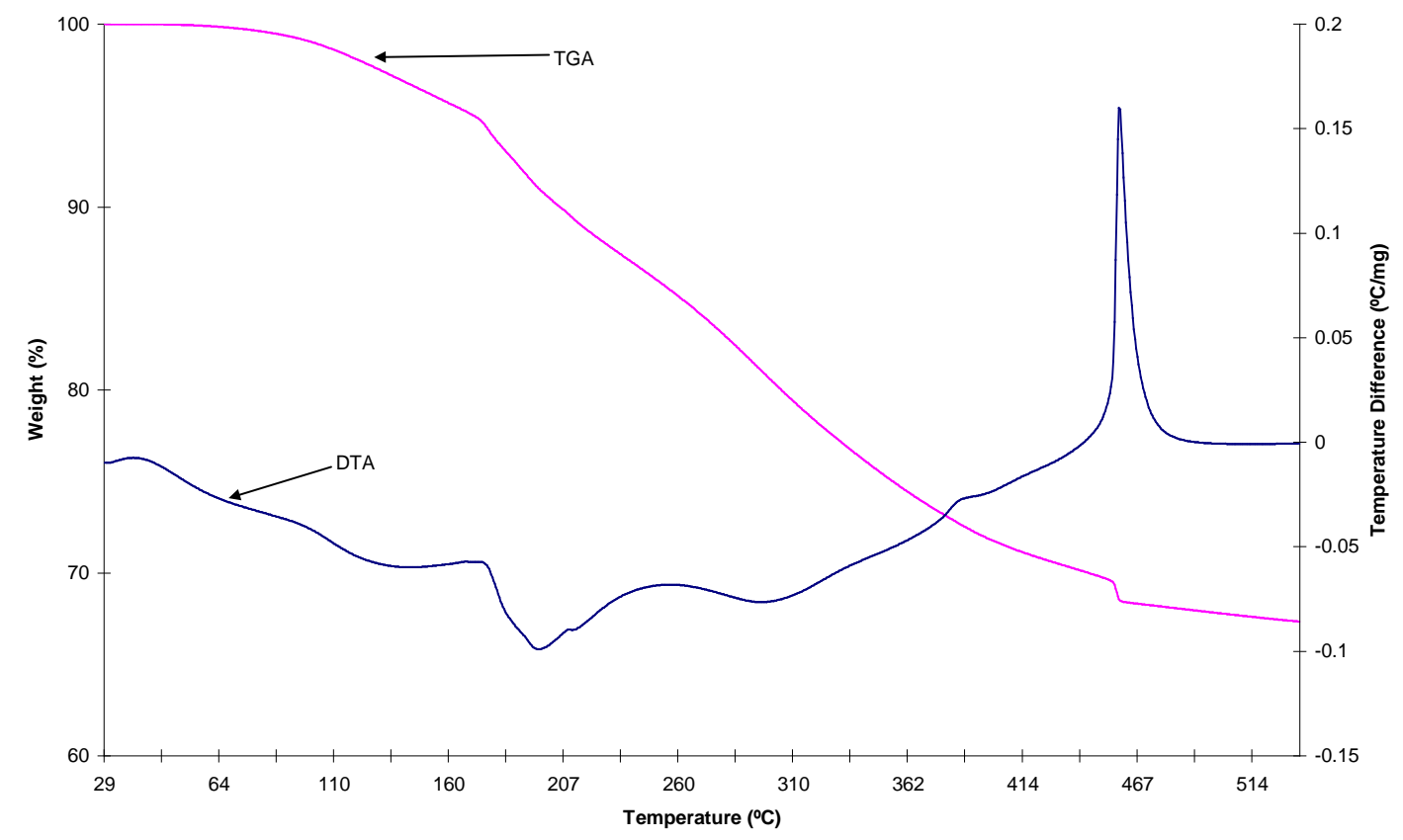

Figure 5 TGA/DTA of $0.81 \mathrm{M}$ solution precipitates $\mathrm{pH} 3$

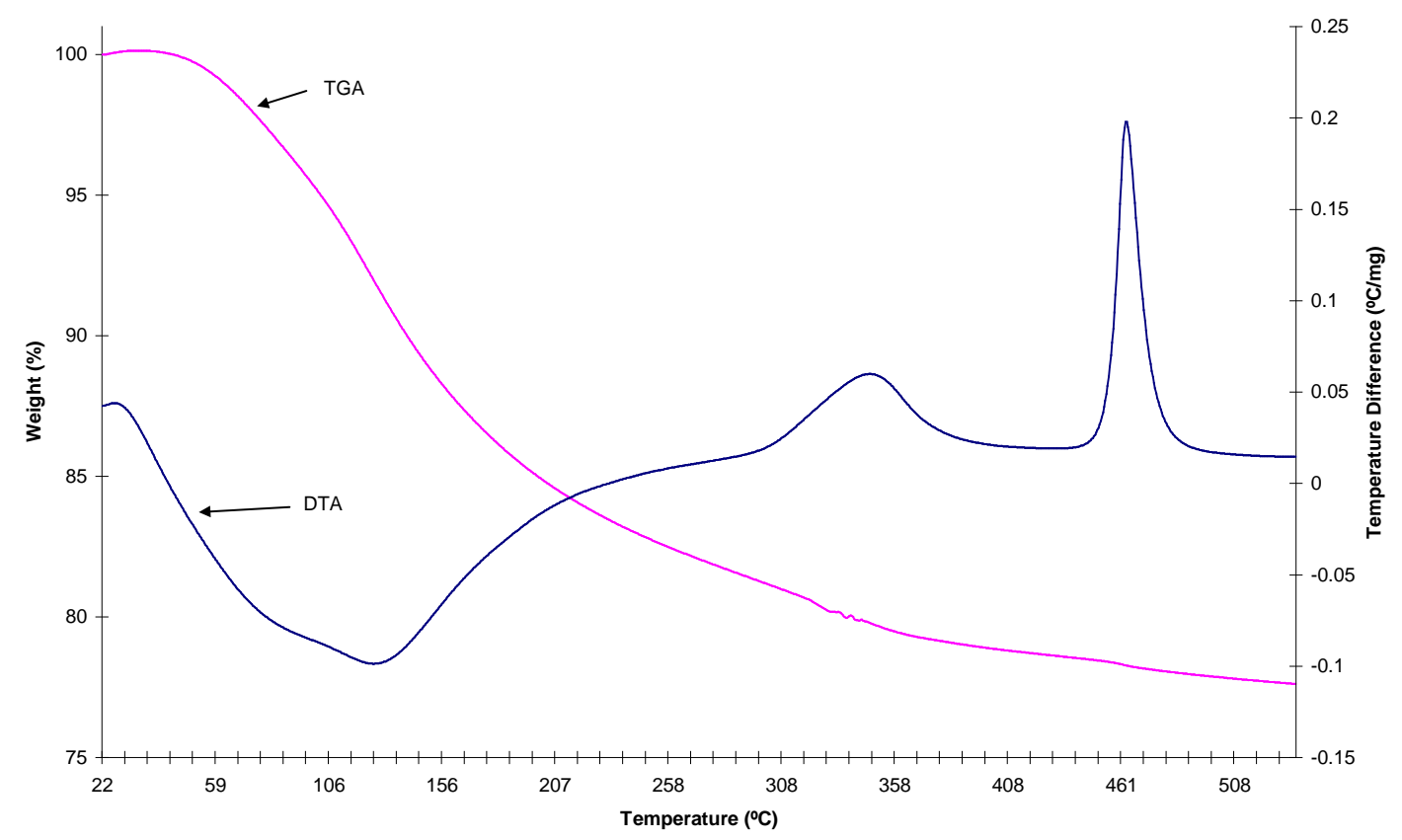

Figure 6 TGA/DTA of $0.81 \mathrm{M}$ solution precipitates $\mathrm{pH} 12$ 


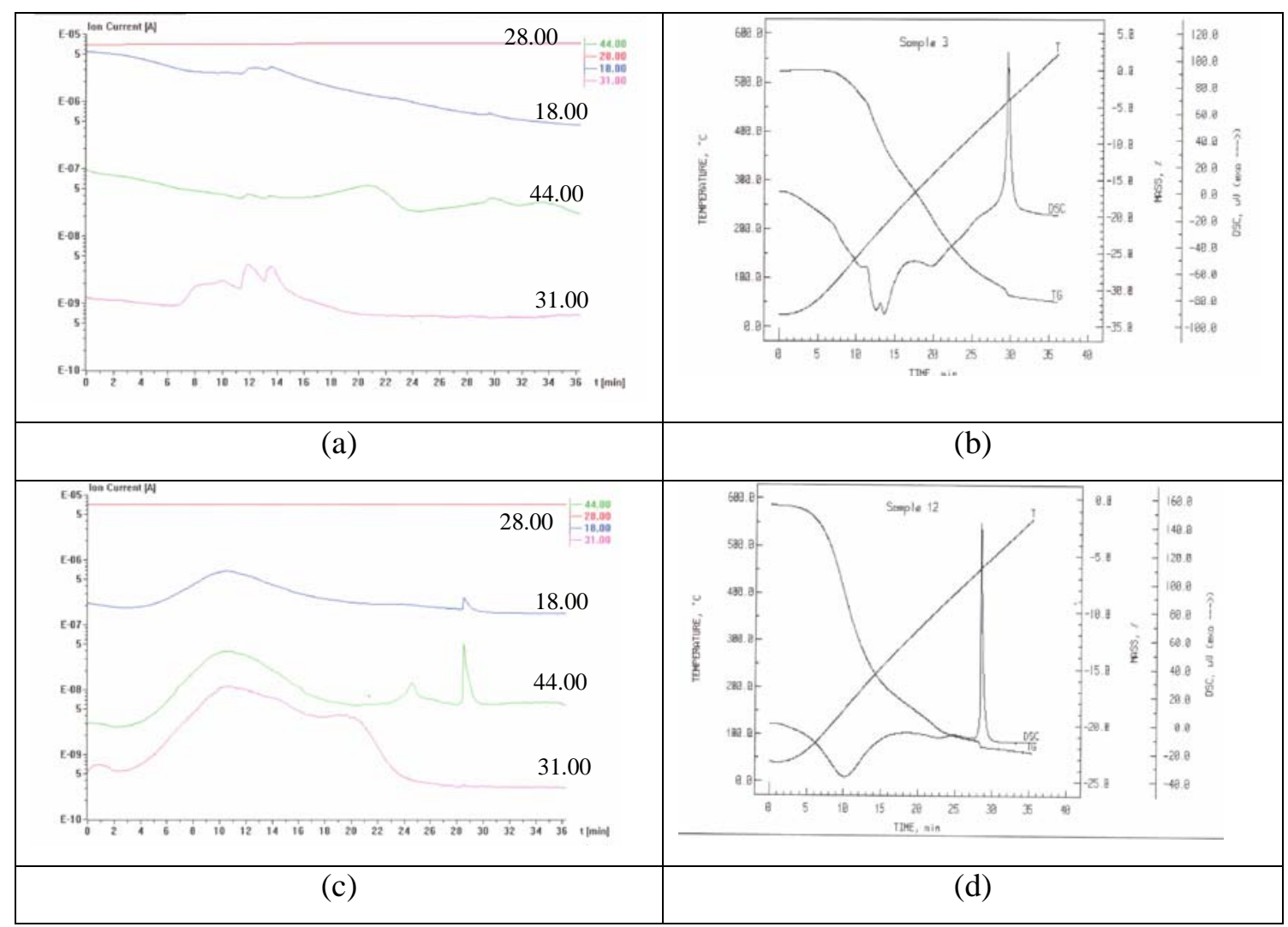

Figure 7 TGA/DTA with Mass Spectrometry, (a) MS output for pH 3 sample (b) TGA/DTA output for $\mathrm{pH} 3$ sample(c) MS output for $\mathrm{pH} 12$ sample (d) TGA/DTA output for $\mathrm{pH} 12$.

To further quantify the products that were being evolved during heating, micro-combustion analysis was preformed on the powders produced at a high agitation with a concentration of $0.81 \mathrm{M}$ precipitated at $\mathrm{pH} 3$ and 12 (Table 2). The $\mathrm{pH} 3$ and 12 powders produced had 9.9\% and $8.2 \%$ mass loss unaccounted for and the values returned in the micro-combustion account well for these masses.

Table 2 Micro-combustion results

\begin{tabular}{|l|l|l|}
\hline element & $\mathrm{pH} 3(\%)$ & $\mathrm{pH} 12(\%)$ \\
\hline $\mathrm{N}$ & 4.52 & 0.2 \\
\hline $\mathrm{C}$ & 0.29 & 3.34 \\
\hline $\mathrm{H}$ & 2.81 & 2.40 \\
\hline Total \% evolved & 7.62 & 5.94 \\
\hline
\end{tabular}


In the case of the powder produced at $\mathrm{pH} 3$ the micro-combustion results agree well with the XRD results by showing a high nitrogen signature indicating the presence of ammonium chloride whilst the $\mathrm{pH} 12$ show only limited nitrogen and higher $\mathrm{C}$ consistent with the presence of ethanol as proposed previously [2].

Elinson and Petrov [11] found that zirconium hydroxides produced from strong hot acidic solution (> $1 \mathrm{~N} \mathrm{HCl}$ ) have the structure of $\mathrm{Zr}[\mathrm{OH}]_{4}$ whilst those produced in weakly acidic solutions were chiefly $\mathrm{ZrO}[\mathrm{OH}]_{2}$. This is in agreement with the structures proposed above. Guo et al [14] alternatively proposed that the structure of zirconium hydroxide produced in acid is $\mathrm{Zr}_{4} \mathrm{O}_{3}(\mathrm{OH})_{10} \cdot 6 \mathrm{H}_{2} \mathrm{O}$. They show TGA/DTA curves for gels produced at $\mathrm{pH} 4$ to justify this structure. These TGA/DTA curves are very different from those produced during this work with one possible explanation being experimental differences.

As the structures proposed to be produced at $\mathrm{pH} 3\left(\mathrm{Zr}[\mathrm{OH}]_{4}\right)$ and $12\left(\mathrm{ZrO}[\mathrm{OH}]_{2}\right)$ contain different oxygen to zirconium ratios, samples of each were investigated for the $\mathrm{O} w \mathrm{t} \%$ using TEM EDS. The $\mathrm{O}$ wt\% returned by EDS for both the $\mathrm{pH} 3$ and 12 precipitated powders as well as a sample of monoclinic zirconium powder (supplied by Millennium Specialty Chemical Rockingham 2003 Z0.5) are shown in Figure 8.

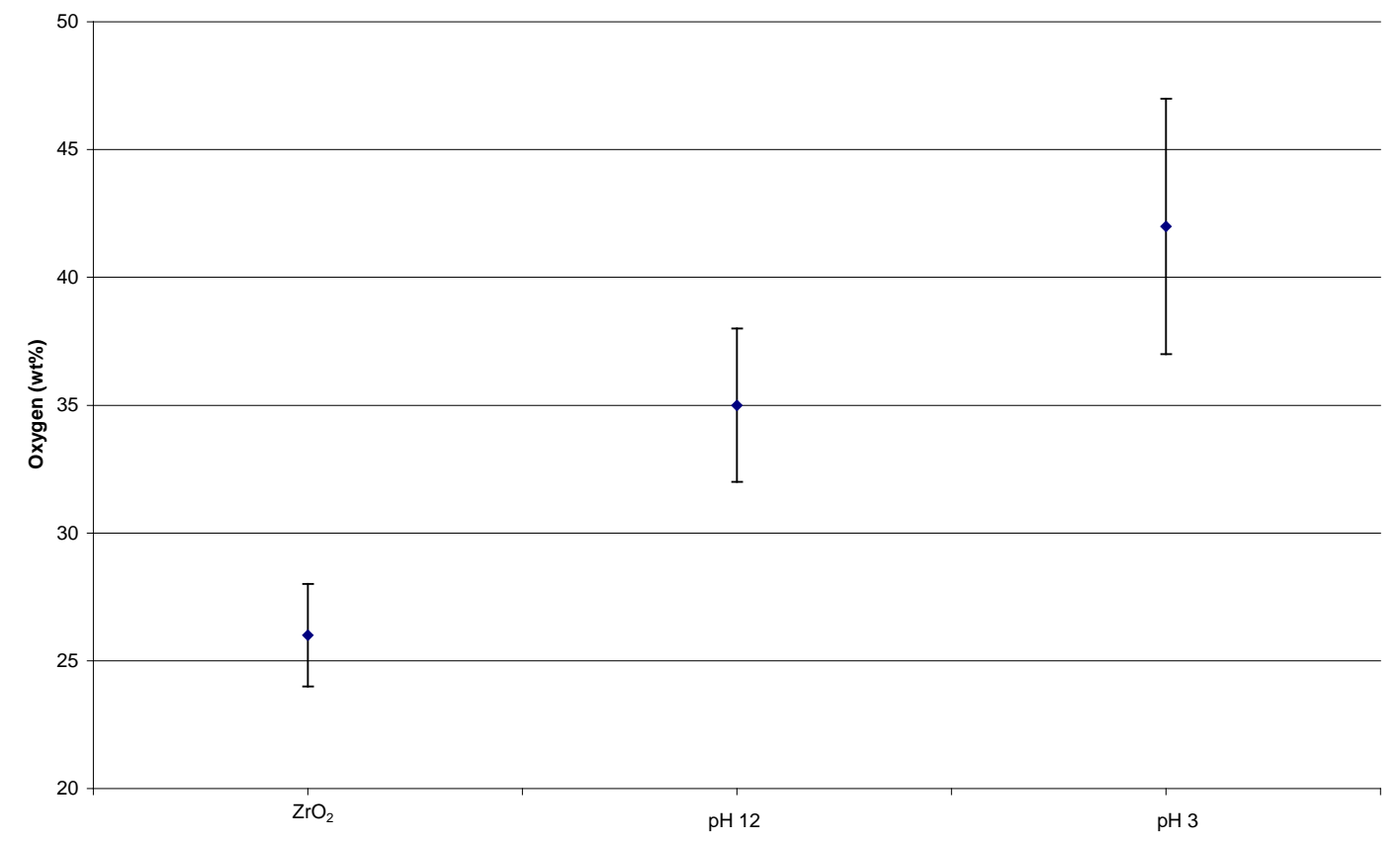

Figure 8 Oxygen wt\% from TEM EDS for $\mathrm{pH}$ 3, and 12 produced powders as well as a monoclinic zirconia sample. 
Although EDS spectroscopy is not an ideal technique for quantitative determination of light elements the authors have successfully used this method to determine Al:O ratios in wear debris from alumina ceramics [26]. $\mathrm{ZrO}_{2}$ has $26 \mathrm{wt} \% \mathrm{O}$ which is in close agreement with the monoclinic sample tested; this result validates the method used in relation to these samples. Twenty particles of each material were examined. Whilst within the limits of the experimentation it is difficult to distinguish the amount of oxygen present in the two precipitated samples due to the uncertainties, a trend was evident, with the $\mathrm{pH} 3$ sample having a higher wt\% O than the $\mathrm{pH} 12$ sample. This result supports the premises that the precipitation conducted at $\mathrm{pH} 3$ results in the formation of $\mathrm{Zr}[\mathrm{OH}]_{4}$ whilst the $\mathrm{pH} 12$ precipitation results in a structure most like $\mathrm{ZrO}[\mathrm{OH}]_{2}$ as suggested by TGA/DTA and microcombustion work.

The use of the TEM was made particularly difficult by the samples undergoing transformation due to the high vacuum and beam current. This was particularly evident in the powder produced at $\mathrm{pH} 3$, (see Figure 9) all care was taken to exclude such samples from the statistical analysis used in the EDS. It was however possible to take 3 EDS results from the same $\mathrm{pH} 3$ produced sample one after the other without shifting the beam and obtain decreasing values of wt $\% \mathrm{O}$ for each collection period with the last collection period resulting in a transformation of the sample. Typical values were $45 \mathrm{wt} \% \mathrm{O}$ on the first collection 35 wt $\% \mathrm{O}$ on the second and $29 \mathrm{wt} \% \mathrm{O}$ on the last. This transformation added to the spread of the results and the subsequent increase in the uncertainty's, in addition these values are normalised for $\mathrm{Zr}$ and $\mathrm{O}$ and do not take into account any $\mathrm{H}$.

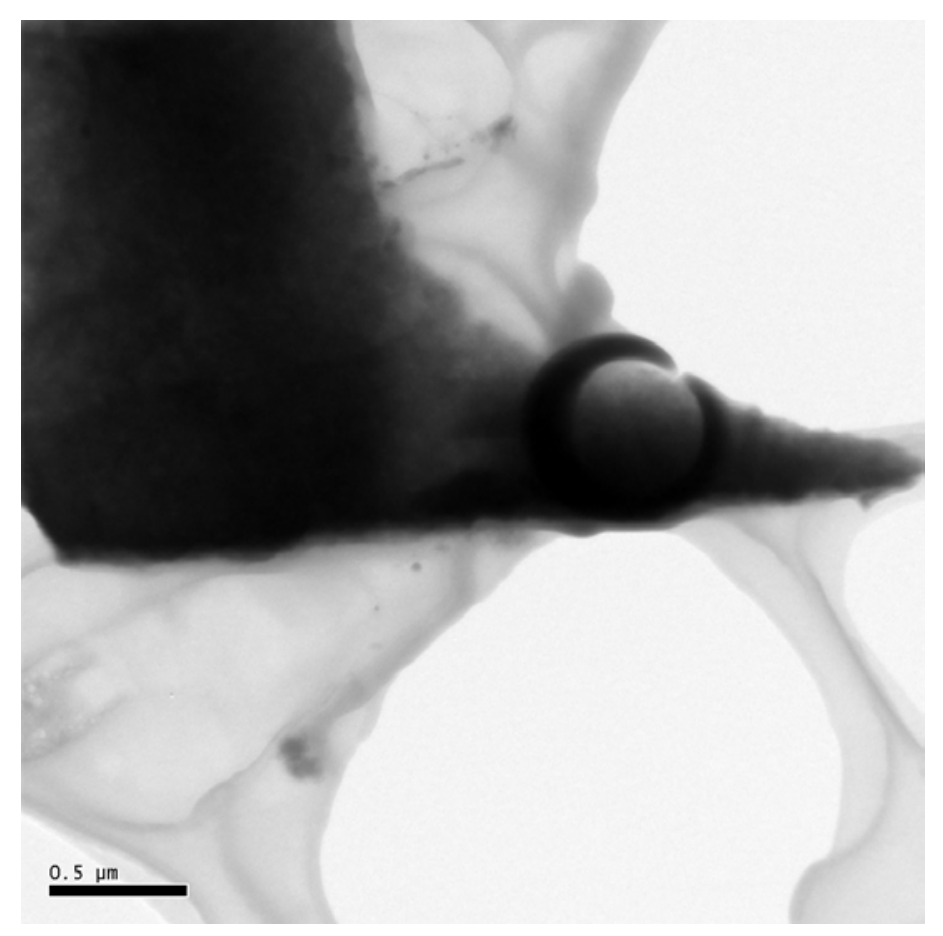


Figure 9 TEM micrograph of $\mathrm{pH} 3$ powder after transformation in TEM

Apart from supporting the structural differences suggested, the TEM work also showed the significant morphological difference in the powders as suggested by the PSD differences and the ability to re-suspend the filter cake. Figure 10 (a) shows a typical particle of the $\mathrm{pH} 3$ powder that has little evidence of being a loose agglomeration; it is more reminiscent of a well compacted cake. In contrast Figure 10 (b) is typical of the $\mathrm{pH} 12$ precipitated powder that has the appearance of a loose aggregation of fine sub particles.

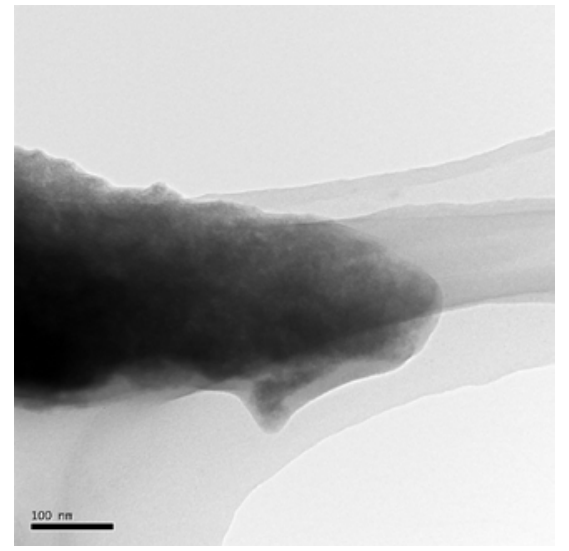

(a)

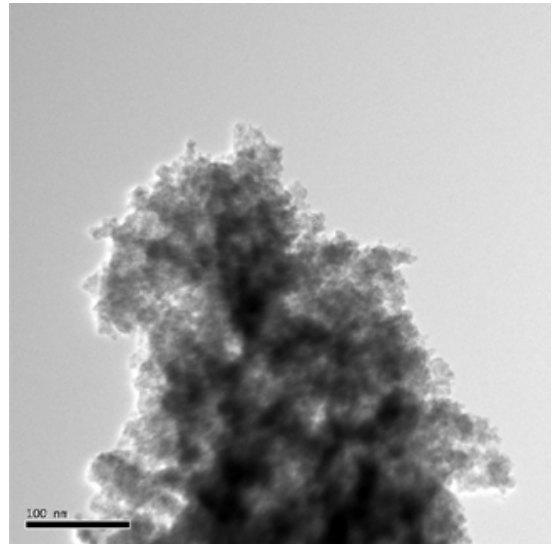

(B)

Figure 10 TEM Micrograph of (a) $\mathrm{pH} 3$ powder and (b) of $\mathrm{pH} 12$ powder

\section{Conclusions}

Concentration of starting solutions, agitation levels and the $\mathrm{pH}$ that the precipitation is conducted at all effect the particle size distribution for the hydrous zirconium that is produced. The largest change is due to $\mathrm{pH}$ with the smallest change occurring when comparing a pH 12 sample with low agitation and a starting concentration of 1.62 M (PS of $743 \mathrm{~nm}$ ) with a pH 3 sample with the other processing parameters remaining the same (3390 $\mathrm{nm}$ ); this is an increase by 4.5 times. The largest change occurred when comparing a $\mathrm{pH} 12$ precipitation with high agitation and $1.62 \mathrm{M}$ solution concentration (PS $73 \mathrm{~nm}$ ) with the same processing parameters except for the precipitation being carried out at $\mathrm{pH} 3(2160 \mathrm{~nm})$ which is an increase of greater than 29 times. The effect of the $\mathrm{pH}$ of precipitation is most remarkable in that it overshadows all of the other processing parameters with the PS being smaller by 1 to 2 orders of magnitude for those samples precipitated at a $\mathrm{pH} 12$ in comparison to those produced at $\mathrm{pH}$ 3. From an industrial processing perspective, the small PS of the 
precipitate at $\mathrm{pH} 12$ (743 to $49 \mathrm{~nm}$ dependent on processing parameters) leads to significant difficulty in filtering which is an important issue.

An order of magnitude change in PS is not limited to $\mathrm{pH}$ changes however as within those precipitations tests carried out at $\mathrm{pH} 12$ changes in the level of agitation also produced order of magnitude differences. The higher agitation in all cases produced smaller PS. As expected lower solutions concentrations were found to produce smaller PS.

The differences seen in the filtering and subsequent differences in morphology of the dried powders, was investigated initially using XRD which showed that those powders produced at $\mathrm{pH} 3$ had retained greater amounts of ammonium chloride. To further investigate the composition of the precipitates TGA/DTA and TGA-MS along with micro-combustion analysis were used with the results suggesting that the $\mathrm{pH}$ of precipitation causes differences in the structure of the hydrated zirconium. The $\mathrm{pH} 3$ powders are thought to have a structure most closely resembling $\mathrm{Zr}[\mathrm{OH}]_{4}$ whilst those produced at $\mathrm{pH} 12$ are consistent with a formulation of $\mathrm{ZrO}[\mathrm{OH}]_{2}$.

TEM with EDS was used to investigate the zirconium to oxygen content of powders produced at both $\mathrm{pH}$ values as well as a zirconia sample. It was found that the $\mathrm{pH} 3$ sample had almost $43 \mathrm{wt} \% \mathrm{O}$ while the $\mathrm{pH} 12$ sample had approximately $32 \mathrm{wt} \% \mathrm{O}$. The difficulty in using TEM EDS for light elements precludes detailed analysis but the results returned are in accordance with the different degrees of hydration suggested by the TGA/DTA, and micro-combustion work. The effect that the differing degrees of hydration has on the ceramic process further down stream in the manufacturing process is unclear.

It makes some sense, however, in operational situations to use lower $\mathrm{pH}$ precipitation as this will have the double benefit of allowing for lower base input with associated cost reduction and the PS that allows for the most economical filtering. The tuning of both solution concentration and agitation may allow for the targeting of specific PS. In all cases, however, the final ceramic properties must be considered. The structural differences and or other differences between the manufacture systems may impact on the final ceramics.

\section{Acknowledgements}


G.C, C.B and M.O acknowledge the financial support of the Australian Research Council (ARC) for ARC linkage grant LP0561922, and CB acknowledges the financial support of the ARC for REIF grant R00107962, which enabled the SAXS studies to be undertaken. G.C, is the holder of an Australian Postgraduate Award (Industry) and AINSE Postgraduate Research Award.

\section{References}

1. Carter, G.A., et al., Ammonia-induced precipitation of zirconyl chloride and zirconyl-yttrium chloride solutions under industrially relevant conditions. Powder Technology. In Press, Corrected Proof doi:10.1016/j.powtec.2008.04.087.

2. Rajendran, S., Production of Nano-Crystalline Zirconia Powders and Fabrication of High Strength Ultra-Fine-Grained Ceramics. Materials Forum 1993. 17: p. 333-350.

3. Lauci, M., . Powders Agglomeration Grade in the ZrO2-Y2O3 Coprecipitated Process. Key Engineering Materials, 1997. 132-136: p. 89-92.

4. Clearfield, A., Structural Aspects of Zirconium Chemistry Review. Pure and Applied Chemistry, 1964. 14: p. 91-108.

5. Elinson S. V. and Petrov K. I., Analytical Chemistry of Zirconium and Hafnium. 1969, London Ann Arbor-Humphrey Science Publishers.

6. Larsen E. M. and Gammill M., Electrometric Titrations of Zirconium and Hafnium Solutions'. American Chemical Society 1950. Vol. 72: p. 3615-3619

7. Kovalenko and Bagdasaov, The Solubility of Zirconium Hydroxide. Russian Journal of Inorganic Chemistry 1961. 6(3): p. 272-275.

8. Huang C., Tang Z., and Zhang Z., Differences between Zirconium Hydroxide $(\mathrm{Zr}(\mathrm{OH}) 4 \varangle \mathrm{nH} 2 \mathrm{O})$ and Hydrous Zirconia ( $\mathrm{ZrO} 2 \varangle \mathrm{nH} 2 \mathrm{O})$. Journal of American Ceramic Society, 2001. 84(7): p. 1637-1638.

9. Britton, Electrometric Studies of the precipitation of hydroxides. Part 2. Journal of the Chemical Society Transactions 1925. 127(2): p. 2120-2141.

10. Singh, R.P. and N.R. Banerjee, Electrometeric Studies on the precipitation of hydrous oxides of some Quadravalent Cations. Part 1. Precipitation of Zirconium Hydroxide from solutions of zirconium salts. Journal Indian Chemical Society, 1961. 38(11): p. 865-870.

11. Elinson, S.V. and K.I. Petrov, Analytical Chemistry of Zirconium and Hafnium. Analytical Chemestry of Elements. 1969, London Ann ArborHumphrey Science Publishers.

12. Zaitsev, L.M. and G.S. Bochkarev, Peculiarities in the behaviour of zirconyl in solutions. Russian Journal of Inorganic Chemistry 1962. 7(4): p. 411-414. 
13. Solovkin, A.S. and S.V. Tsvetkova, The Chemistry of Aqueous Solutions of Zirconium salts (Does The Zirconyl Ion Exist?). Russian Chemical Reviews 1962. 31(11): p. 655-669.

14. Guo, G.-Y., Y.-L. Chen, and W.-J. Ying, Thermal, spectroscopic and X-ray diffractional analyses of zirconium hydroxides precipitated at low $\mathrm{pH}$ values. Materials Chemistry and Physics, 2004. 84(2-3): p. 308-314.

15. Guo, G.-Y. and Y.-L. Chen, A nearly pure monoclinic nanocrystalline zirconia. Journal of Solid State Chemistry, 2005. 178(5): p. 1675-1682.

16. Clearfield, A., The Mechanism of Hydrlytic Polymerization of Zirconyl Solutions. Journal Materials Research, 1990. 5(1): p. 161-162.

17. Garvie, R.C., The Occurrence of Metastable Tetragonal Zirconia as a Crystalite Size Effect. Journal of Physical Chemestry, 1965. 69 (4): p. 6.

18. Roosen, A. and H. Hausner, Techniques for Agglomeration Control During Wet-Chemical Powder Synthesis. Advanced Ceramic Materials 1988. 3(2): p. 131-37.

19. Pietsch, W., Size Enlargement by Agglomeration. 1991, Baffins Lane Chichester Sussex England: John Wiley and Son

20. Myerson, A., Handbook of Industrial Crystallization Second edition. 2002, Boston 225 Wildwood Ave Woburn MA 01801-2041,

: Butterworth Heinemann.

21. Carter G., et al., From Zirconyl Chloride to Zirconia Ceramic, A Plant Operation Perspective. Materials Forum, 2008. 32-2008: p. 82-89.

22. Perry, R. and D. Green, Perry's Chemical Engineers Handbook seventh edition. 1997, New York USA, : McGraw-Hill

23. Lorimer, G.W., Quantitative x-ray microanalysis of thin specimens in the transmission electron microscope; a review. Mineralogical Magazine., 1987. 51: p. 49 - 60.

24. Jepson, W.B. and J.B. Rowse, The composition of kaolinite-an electron microprobe study. Clays and Clay Minerals, 1975. 23: p. 310 - 317.

25. Matsui, K., et al., 'Raman Spectroscopic Studies on the Formation Mechanism of Hydrous-Zirconia Fine Particles'. Journal of American Ceramic Society, 1995. 78(1): p. 146-52.

26. Carter, G.A., A. van Riessen, and R.D. Hart, Wear of Zirconia Dispersed Alumina at Ambient, $140^{\circ} \mathrm{C}$ and $250^{\circ} \mathrm{C}$. Journal of the European Ceramic Society, , 2006. 26: p. 3547-3555. 